\title{
Trial Screening
}

National Cancer Institute

\section{Source}

National Cancer Institute. Trial Screening. NCI Thesaurus. Code C48262.

A process of active consideration of potential subjects for enrollment in a trial. 